\title{
DETERMINAÇÃO DE ÁCIDO ACÉTICO EM AMOSTRA DE VINAGRE ADULTERADA COM ÁCIDO CLORÍDRICO - UM EXPERIMENTO INTEGRADO DE TITULAÇÃO POTENCIOMÉTRICA E CONDUTOMÉTRICA
}

\author{
José Vinicius Martins, Ana Paula Ruas de Souza, Maiara Oliveira Salles e Silvia Helena Pires Serrano* \\ Instituto de Química, Universidade de São Paulo, Av. Prof. Lineu Prestes, 748, Cidade Universitária, 05508-900 São Paulo - SP, Brasil
}

Recebido em 8/5/09; aceito em 9/9/09; publicado na web em 24/2/10

\begin{abstract}
DETERMINATION OF ACETIC ACID IN VINEGAR ADULTERATED SAMPLE WITH CLORIDRIC ACID - AN EXPERIMENT INTEGRATED OF POTENTIOMETRIC AND CONDUCTOMETRIC TITRATIONS. The determination of acetic acid in vinegar adulterated sample using simultaneous potentiometric and condutometric titrations was used as an example of integrated experiment in instrumental analysis. An Excel ${ }^{\circledR}$ spreadsheet, which allows the entry of simultaneous data and the construction of the superimposed experimental curves (condutometric, potentiometric, first and second derivative potentiometric curve and, distribution diagrama of the acetic species as function of $\mathrm{pH}$ ), was used as powerful tool to discuss the fundamental concepts involved in each technique and choose the best of them to quantify, without mutual interference, $\mathrm{H}_{3} \mathrm{CCOOH}$ and $\mathrm{HCl}$ in vinegar adulterated sample.
\end{abstract}

Keywords: vinegar adulterated sample; simultaneous potentiometric and condutometric titrations and fundamental concepts.

\section{INTRODUÇÃO}

Um dos maiores problemas enfrentados pelos docentes nos cursos de graduação é a dificuldade de auxiliar os estudantes a construir o conhecimento de forma integrada, desenvolvendo espírito crítico e facilidade de comparação de conteúdos diferentes, com o objetivo de aplicá-los na resolução de problemas reais. Sob este aspecto, a experimentação tradicional, em que o dado experimental tem a função única de corroborar a teoria dita aceita (ensinada) deve ser substituída pela construção de conceitos em diálogo entre o que os alunos aprenderam em cursos anteriores e os novos conceitos que se objetiva construir. ${ }^{1,2}$

Outro aspecto a ser considerado para a experimentação em ciências é a diferença entre experimentos científicos e experimentos voltados para o ensino de determinado conceito. $\mathrm{O}$ trabalho experimental desenvolvido durante os cursos de graduação deve transcender a mera aplicabilidade de conceitos já estudados em sala de aula, não sendo meramente manipulativo, ou seja, o aluno deve ser autor crítico do trabalho experimental para que, em nova situação, se sinta preparado para a resolução de determinado problema. Entretanto, cada vez mais os estudantes terminam os cursos despreparados para esta tarefa e, na maioria das vezes, isto se deve à própria metodologia de ensino que induz a um aprendizado compartimentalizado.

Uma alternativa para maximizar o aprendizado do aluno surgiu no decorrer de aulas de laboratório da disciplina Eletroquímica e Eletroanalítica, ministrada para os estudantes do terceiro ano de Química do Instituto de Química da USP e foi avaliada durante o desenvolvimento do Programa de Monitoria para Alunos de Graduação e do Projeto PAE (Programa de Aperfeiçoamento de Ensino), em que a ampla participação dos estudantes de Graduação, Mestrado e Doutorado é altamente recomendada, considerando a formação futura dos mesmos para docência em ensino superior. Além disso, a formação do indivíduo é sempre um fator essencial para levar a uma atuação adequada em qualquer situação profissional, fato que somente o grau de titulação não garante. ${ }^{3}$

O número elevado de alunos, a necessidade de atender a diversos grupos de estudantes, que trabalham em sistema de rodízio de técni-

*e-mail: shps@iq.usp.br cas, somado à dificuldade dos mesmos em apresentarem relatórios contendo uma comparação crítica entre os diferentes métodos estudados, levou à ideia de integrar ao menos duas técnicas diferentes em um único experimento.

Para tanto, escolheu-se como exemplo a integração das técnicas condutométrica e potenciométrica para quantificação de $\mathrm{HCl}$ e $\mathrm{H}_{3} \mathrm{CCOOH}^{4}$ em mistura (vinagre adulterado com ácido clorídrico).

Para facilitar as discussões acerca dos princípios básicos envolvidos nos dois sistemas de detecção, desenvolveu-se uma planilha (Microsoft Excel $^{\circledR}$ ), com a qual as curvas condutométricas e potenciométricas são construídas enquanto os alunos obtêm os dados experimentais. Assim, os dados são lançados na base de entrada da planilha e as curvas experimentais de titulação são traçadas de forma simultânea em um mesmo gráfico, permitindo que as diferenças entre os resultados fornecidos pelos dois sistemas de detecção sejam rapidamente constatadas. De forma similar, são traçadas as curvas de distribuição de espécies $\left(\mathrm{H}_{3} \mathrm{CCOOH}\right.$ e $\left.\mathrm{H}_{3} \mathrm{CCOO}^{-}\right)$como função do $\mathrm{pH}$ medido, bem como as derivadas $\left(1^{\mathrm{a}}\right.$. e $2^{\mathrm{a}}$. ) da curva potenciométrica tradicional.

Esta planilha bastante simples, inspirada no programa CurtiPot, ${ }^{5}$ foi adaptada para o experimento em questão, tendo sido empregada para construção das Figuras 4 - 6, apresentadas neste trabalho. A planilha para entrada de dados, bem como uma versão preenchida como modelo, encontra-se disponível no endereço: http://www2. iq.usp.br/docente/shps/.

A solução mistura contendo os dois ácidos foi titulada com solução de $\mathrm{NaOH}$, monitorando-se simultaneamente as variações de condutância e pH do meio, como forma de determinar o volume de titulante gasto no ponto estequiométrico das reações de neutralização envolvidas.

Particularmente neste exemplo, a detecção condutométrica apresenta vantagens frente à detecção potenciométrica devido ao método empregado para determinação dos volumes de titulante gastos na neutralização de cada um dos ácidos que compõem a mistura.

Na técnica condutométrica, aproveita-se a diferença de condutividade iônica à diluição infinita, $\lambda \mathrm{o}$, dos íons $\mathrm{H}^{+}$e $\mathrm{OH}^{-}(349,6$ e 198,0 .10 $0^{-4} \mathrm{~S} \mathrm{~m}^{2} \mathrm{~mol}^{-1}$, respectivamente) frente a outros íons (por exemplo, $\mathrm{Na}^{+}$e $\mathrm{H}_{3} \mathrm{CCOO}$, com $\lambda \mathrm{o}$ igual a, respectivamente, $50,1 \mathrm{e}$ $\left.40,9.10^{-4} \mathrm{~S} \mathrm{~m}^{2} \mathrm{~mol}^{-1}\right),{ }^{6}$ para obter segmentos lineares, cujos pontos 
de intersecção indicam, com exatidão e precisão necessária, os dois pontos estequiométricos. ${ }^{7} \mathrm{O}$ fato de não haver necessidade de utilizar pontos experimentais na região do ponto estequiométrico se constitui em uma das grandes vantagens da técnica condutométrica frente às titulações potenciométricas, Figura 1.

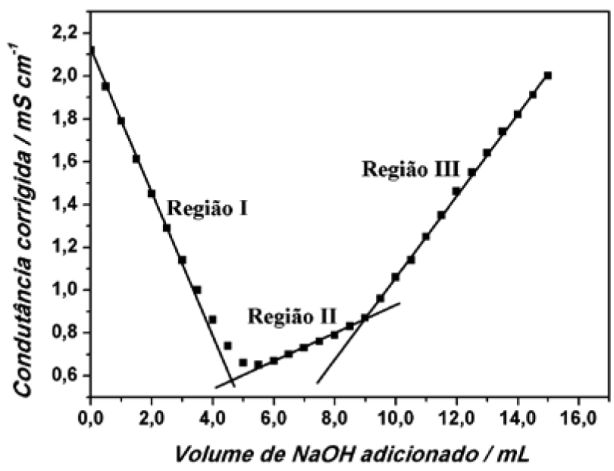

Figura 1. Titulação condutométrica de $25,0 \mathrm{~mL}$ de solução (após diluição) de vinagre adulterado com ácido clorídrico, com $\mathrm{NaOH} \mathrm{0,1} \mathrm{mol} \mathrm{L}^{-1}$. Célula constituída por dois eletrodos de Pt com área de $1 \mathrm{~cm}^{2}$, distanciados entre si por $1 \mathrm{~cm}$

A Figura 1 apresenta três regiões lineares: Região I, na qual ocorre a neutralização do ácido clorídrico (diminuição drástica de condutividade devido à troca de íons $\mathrm{H}^{+}$por $\mathrm{Na}^{+}$), Região II, na qual ocorre a neutralização do ácido acético (aumento brando de condutividade devido à formação de íons $\mathrm{H}_{3} \mathrm{CCOO}^{-}$e do acréscimo de $\mathrm{Na}^{+}$) e Região III, que corresponde à presença do excesso de titulante, $\mathrm{NaOH}$ (crescimento mais acentuado de condutividade devido à entrada de íons $\mathrm{OH}^{-}$com alta condutividade iônica à diluição infinita, $\lambda_{\mathrm{o}}$, além da entrada de íons $\mathrm{Na}^{+}$). Somente os primeiros pontos da região relacionada à titulação do ácido clorídrico (Região I) são utilizados para traçar o segmento linear, utilizando-se como argumento, o fato de que nesta condição, a concentração de íons $\mathrm{H}_{3} \mathrm{O}^{+}$é suficientemente alta para reprimir a ionização do ácido acético. Assim, o $\mathrm{HCl}$ poderia ser titulado sem a interferência do ácido acético. No decorrer da titulação, a concentração de $\mathrm{HCl}$ diminui e, ao final, o efeito do íon comum vai progressivamente deixando de existir, de modo que os dois ácidos passam a ser titulados concomitantemente. No entanto fica a questão: quais pontos, no início da curva condutométrica, realmente satisfazem a condição de reprimir a ionização do ácido acético? A resposta a esta questão é diretamente obtida a partir da curva de distribuição das espécies $\left(\mathrm{H}_{3} \mathrm{CCOOH}\right.$ e $\left.\mathrm{H}_{3} \mathrm{COO}^{-}\right)$como função do $\mathrm{pH}$.

$\mathrm{Na}$ técnica potenciométrica, ${ }^{7-9}$ a determinação do volume de titulante gasto é efetuada utilizando-se obrigatoriamente os pontos experimentais obtidos no intervalo do salto de $\mathrm{pH}$ e/ou potencial que acompanha os dois pontos estequiométricos, justamente em uma região na qual a resposta do eletrodo de vidro é mais lenta e instável. Assim como no caso da volumetria clássica, em que indicadores ácido-base são empregados, o salto potenciométrico é tanto maior quanto maior for a força do ácido e/ou sua concentração em solução, como pode ser observado na Figura 2, que representa titulações de soluções de ácido clorídrico e acético, individualmente, com solução de hidróxido de sódio $0,1 \mathrm{~mol} \mathrm{~L}{ }^{-1}$. Os volumes correspondentes aos pontos estequiométricos são normalmente obtidos por meio da primeira ou segunda derivada da curva potenciométrica.

No caso da titulação de uma mistura contendo um ácido forte e outro fraco, a situação se inverte e a variação de $\mathrm{pH}$ no ponto estequiométrico para a titulação do ácido forte pode até ser menor do que aquela observada durante a titulação do ácido fraco, como ocorre neste caso.

Assim sendo, o objetivo deste trabalho é demonstrar a possibilida-



Figura 2. Curvas de titulação potenciométrica: (a) titulação de solução de ácido acético 0,2 mol $L^{-1}$, preparada a partir de vinagre comercial e (b) titulação de ácido clorídrico 0,2 mol $\mathrm{L}^{-1}$. Ambas as soluções tituladas com solução de $\mathrm{NaOH} \mathrm{0,1} \mathrm{mol} \mathrm{L}^{-1}$

de de introduzir, de forma integrada, conhecimentos teórico-práticos aos estudantes minimizando a tendência do curso de graduação de fornecer conhecimento de forma fragmentada. Além das vantagens didáticas, existe também a economia de tempo e reagentes. Assim, o tempo que os estudantes consumiriam para efetuar as determinações potenciométrica e condutométrica separadamente, pode ser utilizado na discussão dos resultados, ainda durante a aula de laboratório.

\section{PARTE EXPERIMENTAL}

\section{Soluções}

Solução de vinagre adulterada com ácido clorídrico

A solução de vinagre adulterado foi preparada pela adição de 55,0 $\mathrm{mL}$ de vinagre comercial e $8,35 \mathrm{~mL}$ de $\mathrm{HCl}$ 6,0 $\mathrm{mol} \mathrm{L}^{-1}$ em balão volumétrico de 250,0 mL, completando-se o volume com água destilada.

Soluções de acido clorídrico e acido acético

A solução de $\mathrm{HCl} 0,2 \mathrm{~mol} \mathrm{~L}^{-1}$ foi preparada diluindo-se ácido clorídrico concentrado (Merck ${ }^{\circledR}$ ) em água destilada.

A solução de ácido acético $0,2 \mathrm{~mol} \mathrm{~L}^{-1}$ foi preparada a partir da diluição de ácido acético concentrado $\left(\right.$ Vetec $\left.^{\circledR}\right)$ em água destilada.

\section{Solução de hidróxido de sódio}

A solução de $\mathrm{NaOH} 0,1 \mathrm{~mol} \mathrm{~L}^{-1}$ foi preparada dissolvendo-se quantidade apropriada do sólido $\left(\right.$ Merck $\left.^{\circledR}\right)$ em água destilada previamente fervida para eliminação de $\mathrm{CO}_{2(\mathrm{~g})}$ dissolvido. Esta solução não foi padronizada, pois o objetivo do experimento é comparar o desempenho das duas técnicas e não realizar uma determinação quantitativa de concentrações.

\section{Equipamentos}

As medidas de condutividade foram efetuadas utilizando-se um condutivímetro Digimed ${ }^{\circledR}$ modelo DM31 e célula condutométrica constituída por dois eletrodos de platina separados por $1 \mathrm{~cm}$ de distância. As medidas de $\mathrm{pH}$ foram efetuadas com um $\mathrm{pH}$-metro da Digimed ${ }^{\circledR}$ modelo DM20 acoplado a um eletrodo de vidro combinado que utiliza um eletrodo de $\mathrm{Ag} / \mathrm{AgCl}, \mathrm{KCl}$ sat. como eletrodo de referência externo.

\section{Determinação de ácido acético e clorídrico em vinagre}

Utilizou-se como recipiente para a realização das titulações condutométricas um béquer de $250 \mathrm{~mL}$ imerso em outro de $400 \mathrm{~mL}$ contendo aproximadamente $100,0 \mathrm{~mL}$ de água. O objetivo deste 
procedimento foi minimizar o aquecimento da solução de medida, devido ao aquecimento promovido pelo agitador magnético.

Uma alíquota de $10,0 \mathrm{~mL}$ da amostra de vinagre adulterado foi transferida para um balão de 100,0 mL e o volume completado com água destilada. Após homogeneização desta última solução, pipetou-se 25,0 $\mathrm{mL}$ para o béquer de $250 \mathrm{~mL}$, adicionando-se em seguida 75,0 mL de água destilada. Introduziram-se então neste béquer a célula condutométrica, o eletrodo de vidro (previamente calibrado com soluções tampão padrão $\mathrm{pH}=4,0$ e 7,0, para possibilitar a posterior construção do diagrama de distribuição) e a barra magnética. Titulou-se a amostra com solução de $\mathrm{NaOH}$ $0,1 \mathrm{~mol} \mathrm{~L}^{-1}$ adicionando-se incrementos idênticos de $0,5 \mathrm{~mL}$ do titulante. A Figura 3 apresenta o esquema da montagem da aparelhagem utilizada.

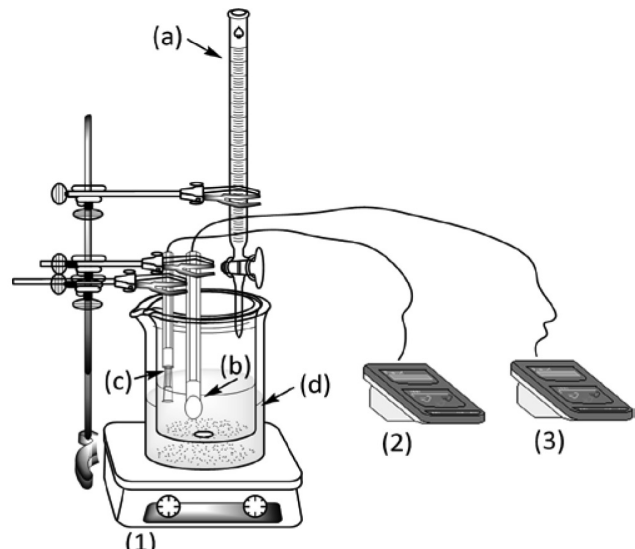

Figura 3. Esquema da montagem utilizada: 1) agitador magnético; 2) condutivímetro; 3) pHmetro; a) bureta (50,0 mL); b) eletrodo de vidro combinado; c) célula condutométrica e d) béquer (com simulação de banho termostático em temperatura ambiente)

\section{RESULTADOS E DISCUSSÃO}

As Figuras 4a, 4b e 4c apresentam a curva condutométrica sobreposta à curva potenciométrica (Figura 4) e à sua primeira e segunda derivadas (Figuras 5 e 6), respectivamente.

Quando a curva de distribuição das espécies é sobreposta à primeira derivada da curva potenciométrica, Figura 1S - material suplementar, ou à segunda derivada, Figura $2 \mathrm{~S}$, os alunos podem observar de imediato que no volume correspondente ao primeiro pico da primeira derivada da curva potenciométrica ou, no volume correspondente ao primeiro cruzamento da segunda derivada com o eixo das abscissas (titulação do $\mathrm{HCl}$ em ambos os casos), já existe uma quantidade que não é desprezível de ácido acético que foi titulada e existe, portanto, na forma de íons acetato, $\% \mathrm{H}_{3} \mathrm{CCOO}^{-}$.

Por outro lado, quando a curva de distribuição das espécies é sobreposta à curva condutométrica, Figura $3 \mathrm{~S}$ - material suplementar, observa-se que no volume estequiométrico correspondente à neutralização do ácido clorídrico, a percentagem de ácido acético presente no meio $\left(\% \mathrm{H}_{3} \mathrm{CCOOH}\right)$ é próxima de $100 \%$. Além disto, é fácil para os estudantes avaliarem quais pontos do primeiro segmento da região linear da curva condutométrica devem ser utilizados para efetuar a extrapolação, que será empregada na determinação do volume de base gasto para a titulação somente do $\mathrm{HCl}$. A figura permite ainda a avaliação imediata da adequação do incremento de volume de titulante adicionado (neste caso, $0,5 \mathrm{~mL}$ ) ou da eventual necessidade de diminuí-lo, de modo a fornecer maior número de pontos experimentais na região em que a espécie preponderante em solução é o ácido acético.

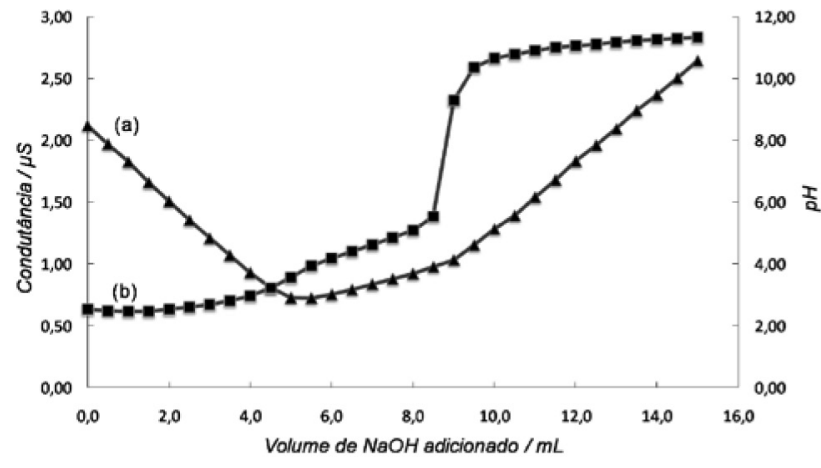

Figura 4. Apresentação simultânea dos resultados obtidos para a titulação condutométrica (a) da amostra (Figura 1) e a titulação potenciométrica (b)

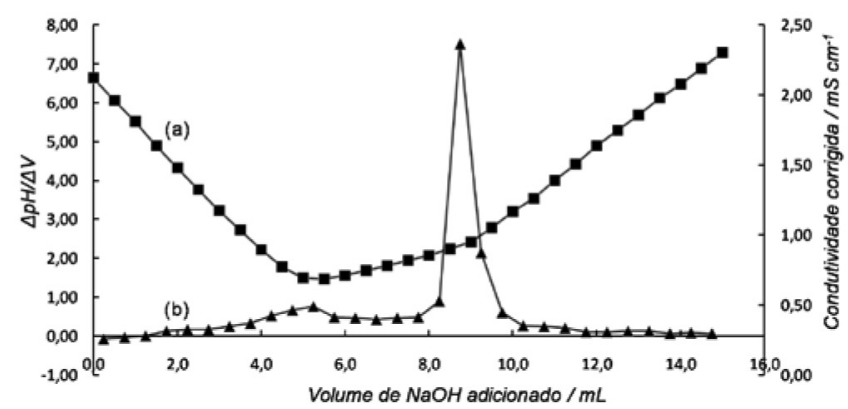

Figura 5. Apresentação simultânea dos resultados obtidos para a titulação condutométrica (a) da amostra (Figura 1) e a primeira derivada da titulação potenciométrica $(b)$

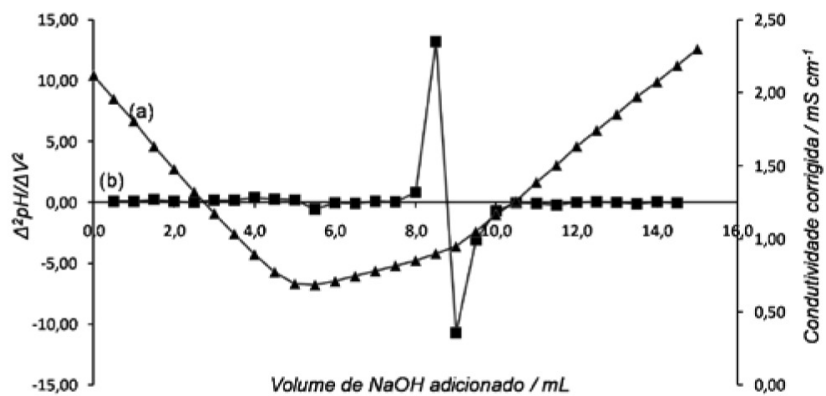

Figura 6. Apresentação simultânea dos resultados obtidos para a titulação condutométrica (a) da amostra (Figura 1) e a segunda derivada da titulação potenciométrica $(b)$

De fato, com base na Figura 3S, pode-se afirmar que somente durante as cinco adições iniciais de $\mathrm{NaOH}$, volume equivalente a $2,5 \mathrm{~mL}$ do titulante, o valor da $\% \mathrm{H}_{3} \mathrm{CCOOH}$ é maior que $99,4 \%$, refletindo assim predominância quase que total da forma protonada do ácido, de modo que adições de $0,2 \mathrm{~mL}$ com certeza permitiriam a obtenção de um maior número de valores experimentais de condutividade na região em que somente o ácido clorídrico é titulado. A extrapolação linear desta região permite então a determinação do ponto estequiométrico sem a necessidade de utilizar maior número de valores experimentais próximos à região do ponto final da titulação, condição imprescindível na técnica potenciométrica.

Outro ponto a ser discutido é o fato do salto potenciométrico relativo à titulação do ácido clorídrico ter sido inferior àquele correspondente à titulação do ácido acético (Figuras 4, 5 e 6), embora o ácido clorídrico 
seja um ácido forte, ao contrário do acético, conforme se observa na Figura 2. Para explicar este dado experimental, é preciso considerar que na titulação de uma solução contendo apenas $\mathrm{HCl}$, a adição de um pequeno volume de base na região do ponto estequiométrico promove uma grande variação no valor de $\mathrm{pH}$ do meio (Figura 2), porém no caso da mistura $\mathrm{HCl}+\mathrm{H}_{3} \mathrm{CCOOH}$, tem-se uma atenuação do salto potenciométrico relativo à neutralização do $\mathrm{HCl}$, resultado da formação de um sistema tampão quando se inicia a titulação do ácido acético. Assim, o salto potenciométrico devido à neutralização do ácido forte se torna menor do que o salto potenciométrico devido à neutralização do ácido fraco, ou seja, ocorre uma inversão da situação representada na Figura 2. Cabe salientar que quanto maior for a concentração de $\mathrm{HCl}$ frente à de $\mathrm{H}_{3} \mathrm{CCOOH}$ na amostra, menor será o $\mathrm{pH}$ inicial e, consequentemente, mais nítido se tornará o salto potenciométrico relativo à titulação do ácido forte. Desta forma, as variações da $1^{\mathrm{a}}$. e $2^{\mathrm{a}}$. derivadas, correspondentes à titulação do $\mathrm{HCl}$, seriam bem maiores e mais definidas se apenas este estivesse presente em solução.

Os volumes de titulante gastos para a titulação potenciométrica do ácido clorídrico $\left(\mathrm{V}_{\mathrm{TP}, \mathrm{HCl}}=5,1\right.$ ou $5,2 \mathrm{~mL}$, valores determinados utilizando-se a $1^{\mathrm{a}}$. e $2^{\mathrm{a}}$. derivadas da curva potenciométrica, respectivamente) foram maiores do que o volume gasto via titulação condutométrica, $\mathrm{V}_{\mathrm{TC}, \mathrm{HCl}}=4,8 \mathrm{~mL}$, o que demonstra que parte do ácido acético foi titulado junto com o ácido clorídrico, embora não haja diferença significativa entre os volumes de titulante encontrados empregando-se a $1^{\mathrm{a}}$. ou a $2^{\mathrm{a}}$. derivadas da curva potenciométrica.

Quando se comparam os volumes de titulante necessários para a titulação do ácido acético via potenciométrica $\left(\mathrm{V}_{\mathrm{TP}, \mathrm{H} 3 \mathrm{CCOOH}}=3,7\right.$ ou $3,8 \mathrm{~mL}$, valores determinados utilizando-se a $1^{\mathrm{a}}$. e $2^{\mathrm{a}}$.derivadas, respectivamente) com aquele gasto via titulação condutométrica $\left(\mathrm{V}_{\mathrm{TC}}\right.$, ${ }_{\text {нзссоон }}=4,2 \mathrm{~mL}$ ), se confirma a previsão de que a neutralização do ácido fraco é iniciada antes do primeiro salto potenciométrico, já que o volume de titulante gasto na titulação condutométrica foi maior, demonstrando que, ao utilizar esta técnica, os dois ácidos foram titulados sem a interferência da neutralização mútua.

\section{CONCLUSÃO}

A integração das técnicas potenciométrica e condutométrica para quantificação de ácido acético em amostras de vinagre adulterado, associada ao desenvolvimento de uma planilha para entrada simultânea de dados e construção de curvas sobrepostas, permite um melhor aproveitamento do tempo e discussão de conceitos fundamentais pertinentes a cada uma das técnicas consideradas, consistindo em ferramenta poderosa para integração e comparação de duas técnicas com características bastante distintas. As dúvidas que antes surgiam e, eventualmente, se perdiam durante a elaboração dos relatórios (fora do ambiente do laboratório), agora podem ser discutidas de imediato, favorecendo o desenvolvimento de senso crítico durante o aprendizado teórico/ prático.
O experimento descrito neste trabalho fez parte do curso de graduação que foi ministrado no primeiro semestre de 2009 e, embora com uma amostragem ainda bastante pequena, foi possível observar que a motivação dos estudantes aumentou, principalmente ao perceberem que inclusive as curvas de distribuição das espécies como função do $\mathrm{pH}$, conteúdo teórico visto no ano anterior, auxilia muito na interpretação dos resultados experimentais.

Adicionalmente, a construção da planilha para analisar os dados experimentais poderia ser realizada pelos próprios alunos, desenvolvendo competências e habilidades relacionadas ao uso das ferramentas de planilhas eletrônicas (como o Excel ${ }^{\circledast}$ ou o OpenOffice - de uso livre).

\section{MATERIAL SUPLEMENTAR}

As Figuras 1S, 2S, 3S e 4S estão disponíveis em http://quimicanova.sbq.org.br, na forma de arquivo PDF, com acesso livre, e apresentam as curvas de distribuição de espécies junto as primeira e segunda derivadas da curva de titulação potenciométrica (1S e 2S, respectivamente); a curva de distribuição junto à curva de titulação condutométrica (3S) e a imagem de um modelo de planilha preenchido (4S).

\section{AGRADECIMENTOS}

À Profa. Dra. M. E. V. Suárez-Iha pelas valiosas sugestões e ao amigo M. A. dos Santos pelas sugestões e agradável companhia.

\section{REFERÊNCIAS}

1. Hodson, D.; Educational Philosophy and Theory 1988, 20, 53.

2. Gonçalves, F. P.; Galiazzi, M. C. Em Educação em Ciências, produção de currículos e formação de professores; Moraes, R.; Mancuso, R., eds.; Ed. Unijuí: Ijuí, 2004, p. 237-252.

3. Arroio, A.; Rodrigues Filho, U. P.; da Silva, A. B. F.; Quim. Nova 2006, 29, 1387.

4. Camochena, S.; Ferreira, E. S.; Synergismus Scyentifica UTFPR 2006, 1,331 .

5. http://www2.iq.usp.br/docente/gutz/, acessada em Maio 2009.

6. Vany'sek, P. Em CRC Handbook of Chemistry and Physics, Internet Version 2005; Lide, D. R., ed., CRC Press: Boca Raton, 2005, Seção 5.

7. Giolito, I.; Métodos Eletrométricos e Eletroanalíticos - Fundamentos e Aplicações, $2^{\mathrm{a}}$ ed., Multitec: São Paulo, 1980.

8. Skoog, D. A.; Holler, F. J.; Nieman, T.; Princípios de Análise Química, $8^{\mathrm{a}}$ ed., Thomson Pioneira: São Paulo, 2006.

9. Harris, D. C.; Análise Química Quantitativa, $7^{\mathrm{a}}$ ed., LTC: Rio de Janeiro, 2008. 


\section{DETERMINAÇÃO DE ÁCIDO ACÉTICO EM AMOSTRA DE VINAGRE ADULTERADA COM ÁCIDO CLORÍDRICO - UM EXPERIMENTO INTEGRADO DE TITULAÇÃO POTENCIOMÉTRICA E CONDUTOMÉTRICA}

José Vinicius Martins, Ana Paula Ruas de Souza, Maiara Oliveira Salles e Silvia Helena Pires Serrano* Instituto de Química, Universidade de São Paulo, Av. Prof. Lineu Prestes, 748, Cidade Universitária, 05508-900 São Paulo - SP, Brasil

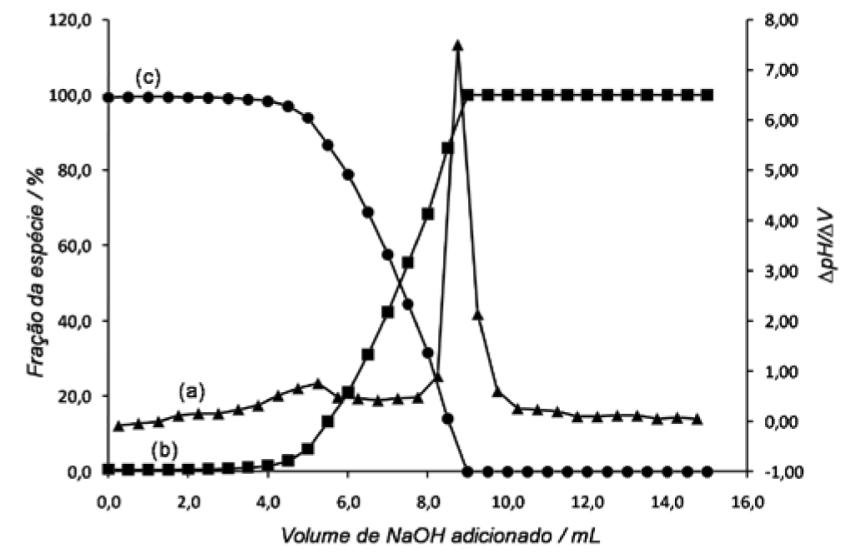

Figura 1S. Primeira derivada da curva potenciométrica de vinagre adulterado (a) e curva teórica de distribuição das espécies $\mathrm{H}_{3} \mathrm{CCOOH}$ e $\mathrm{H}_{3} \mathrm{CCOO}^{-}$(c e b, respectivamente)

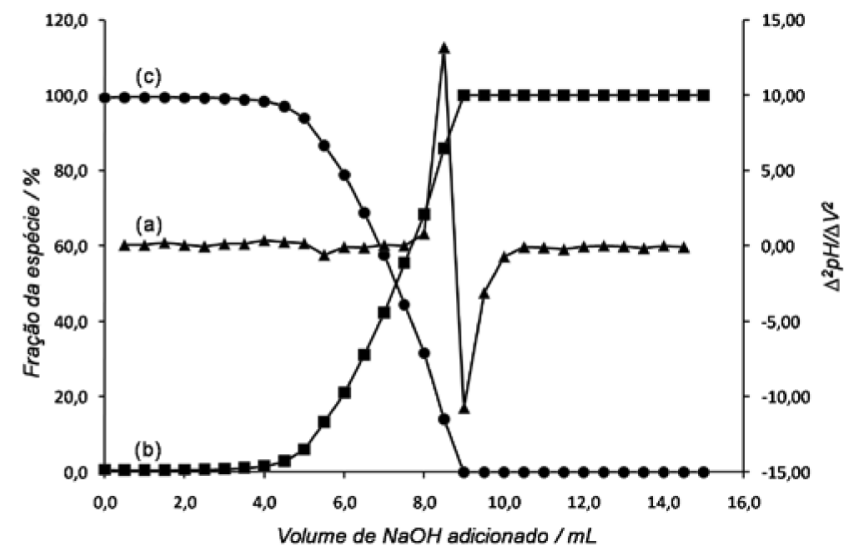

Figura 2S. Segunda derivada da curva potenciométrica de vinagre adulterado (a) e curva teórica de distribuição das espécies $\mathrm{H}_{3} \mathrm{CCOOH}$ e $\mathrm{H}_{3} \mathrm{CCOO}^{-}(\mathrm{c}$ $e b$, respectivamente)

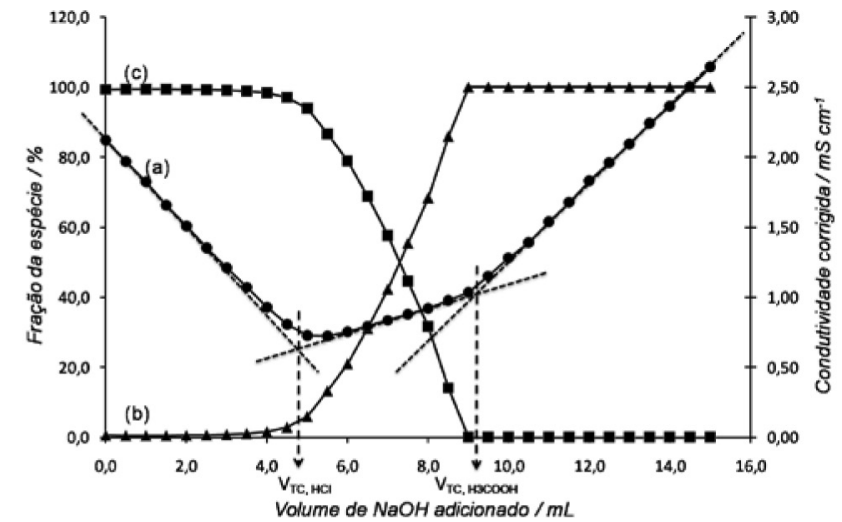

Figura 3S. Curva experimental da titulação condutométrica de vinagre adulterado (a) e curva teórica de distribuição das espécies $\mathrm{H}_{3} \mathrm{CCOOH}$ e $\mathrm{H}_{3} \mathrm{CCOO}^{-}$( $c$ e b, respectivamente) 


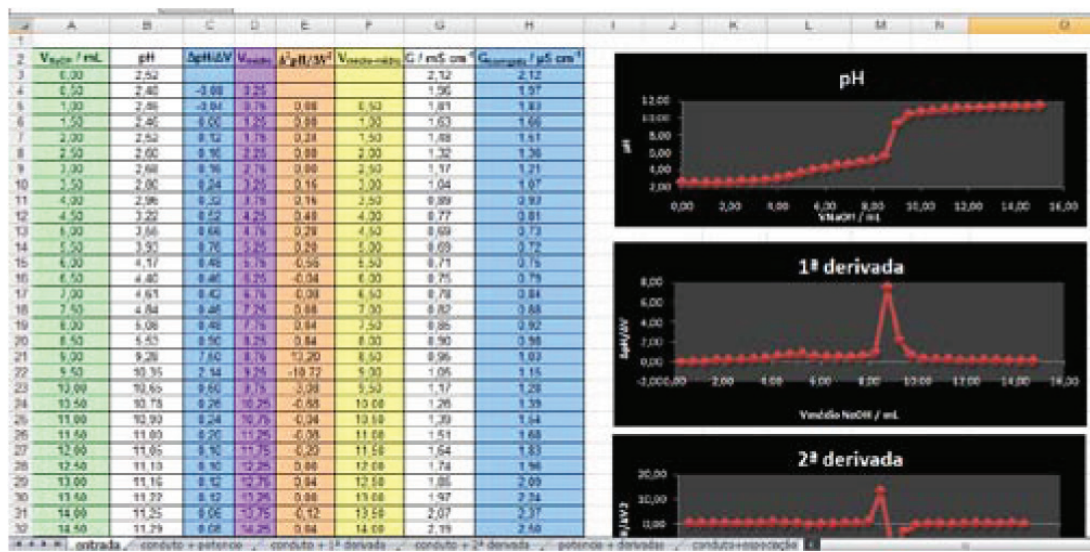

Figura 4S. Imagem do modelo preenchido da planilha para entrada de dados. A planilha eletrônica construída encontra-se disponível em http://www2.iq.usp. br/docente/shps/ 